\title{
Hyperdontia: Exploring the Developmental Abnormality
}

\author{
Naji Ziad Arandi ${ }^{1, A-F}$ \\ ${ }^{1}$ Arab American University, Occupied Palestinian Territories Jenin, Palestine \\ A - Research concept and design, B - Collection and/or assembly of data, C - Data analysis and interpretation, \\ $D$ - Writing the article, E - Critical revision of the article, F - Final approval of article
}

Arandi NZ. Hyperdontia: Exploring the Developmental Abnormality. J Pre-Clin Clin Res. 2020; 14(4): 178-183. doi: 10.26444/jpccr/130372

\begin{abstract}
Introduction and objective. Hyperdontia is a dental developmental anomaly in which supernumerary teeth exist. These are extra teeth to the normal set of primary or permanent dentitions. This article reviews the current literature on hyperdontia in the permanent dentition.

Materials and method. A thorough literature search was carried out using Scopus, PubMed, and Google Scholar databases. Results were reviewed, prioritized, and findings compiled. The key words of the search strategy were: prevalence, case reports, supernumerary, supplemental, distomolars, forth molars, paramolars, parapremolars, mesiodens, and supernumerary lateral incisors. Only articles in English published in peer-reviewed journals were included.

Brief description of the state of knowledge. The prevalence of supernumerary teeth varies between and within different populations. They may cause various aesthetic, occlusal, and functional complications and often require an interdisciplinary intervention. Familiarity with such anomalies is essential for the dental practitioner. Recognition and correct identification of the anomaly is important when communicating with other dental team members, especially in the case of a referral to or from another dental office. Moreover, understanding the anomaly is an important factor in determining the course of treatment, if any.

Conclusion. It is hoped that this review will provide dental practitioners with an update on the classification, characteristics, and prevalence figures for each type of supernumerary tooth.
\end{abstract}

\section{Key words}

distomolar, dental abnormality, paramolar, parapremolars, supplemental lateral incisor, non-syndromic, mesiodens, hyperdontia, supernumerary teeth

\section{INTRODUCTION}

Developmental dental anomalies are marked deviations from the normal presentation of the primary or permanent dentition. These anomalies include changes in the number, morphology, structure, and size of teeth. Anomalies resulting in a variation in the number of teeth include hyperdontia, a dental anomaly in which supernumerary teeth are formed in excess of the normal number. The incidence of hyperdontia is quite rare and falls in the range of $0.04 / 2.7 \%$ [1-9] with a well reported male predilection[1,4,9-12]. Supernumerary teeth may erupt normally, remain impacted, appear inverted, or assume an ectopic position or an abnormal path of eruption. Supernumerary teeth may cause a variety of complications, such as crowding, delayed eruption, rotations, diastemas, cystic lesions, and resorption of adjacent teeth. Therefore, early diagnosis, proper evaluation, and appropriate treatment planning are essential [2].

Traditionally, supernumerary teeth were occasionally found and diagnosed using panoramic radiographs. However, these radiographic images fail to assess the accurate locations of a supernumerary tooth and its spatial relationships with neighboring structures and adjacent teeth, which are necessary for treatment planning. Nowadays, CBCT (Cone Beam Computor Tomography) is advocated to determine, analyze and plan the treatment of supernumeraries based

Address for correspondence: Naji Arandi, Arab American University, Occupied Palestinian Territories

E-mail: arandi@gmail.com

Received:10.10.2020; accepted: 11.11.2020; first published: 02.12.2020 on the accurate $3 \mathrm{D}$ information with regards to the type, shape, and position of the supernumerary tooth, as well as local aberrations and root resorption of adjacent permanent teeth [13]. This article reviews the current literature on hyperdontia in the permanent dentition.

\section{MATERIALS AND METHOD}

A thorough literature search was carried out using Scopus, PubMed, and Google Scholar databases. Results were reviewed, prioritized, and findings compiled. The keywords of the search strategy were: case reports, prevalence, supernumerary, supplemental, distomolars, forth molars, paramolars, parapremolars, mesiodens, and supernumerary lateral incisors. Only articles in English published in peerreviewed journals were included. It was hoped that this review will provide the dental practitioner with an update on the classification, characteristics, and prevalence figures of each type of supernumerary tooth.

Supernumerary teeth occur due to an unclear etiology, whereas, according to many authors, they occur due to the hyperactivity of dental lamina under genetic predisposition $[2,14,15]$. Although the majority of supernumerary cases are non-syndromic, eight very different entities present supernumerary teeth as a distinctive feature: cleidocranial dysplasia, familial adenomatous polyposis, trichorhinophalangeal syndrome type I, RubinsteinTaybi syndrome, Nance-Horan syndrome, Opitz G/BBB syndrome, oculofaciocardiodental syndrome, and Robinow 
syndrome[16]. In general, a supernumerary tooth may closely resemble the teeth of the group to which it belongs (a supplemental or eumorphic supernumerary tooth), i.e. molars, premolars, or anterior teeth, or may bear little resemblance in size or shape to the teeth with which it is associated (a rudimentary of a dysmorphic supernumerary tooth). Supernumerary teeth can also be described according to their orientation (vertical or normal, inverted, and horizontal), or according to their position (buccal, palatal, and transverse) [2]. Most commonly, there is only one supernumerary tooth in a dentition; less frequently there are two supernumeraries, and multiple supernumerary teeth are rare. Multiple supernumerary teeth are more common when a syndrome is involved. When multiple non-syndromic supernumerary teeth are present (>five supernumeraries), the most common site affected is the mandibular premolar region $[17,18]$. There is no definite time for supernumeraries to develop, they may become evident prior to birth, or as late as at ten years of age, developing especially in the premolar region [18].

Supernumerary teeth in the anterior region. Although supernumary teeth may be found in any location in the maxillary or mandibular dental arch, they have a welldocumented predilection for the anterior premaxilla. Supernumeraries in the premaxilla most frequently cause local disturbances, such as midline diastema, delay or prevention in the eruption of the associated permanent incisors, displacement and rotations of the adjacent teeth, crowding and malalignment of the incisors, possible root resorption or dilacerations, development of dentigerous cyst, and migration into the nasal cavity or maxillary sinus [19].

A mesiodens is the supernumerary tooth that occurs in the region between the maxillary central incisors (Fig. 1). They

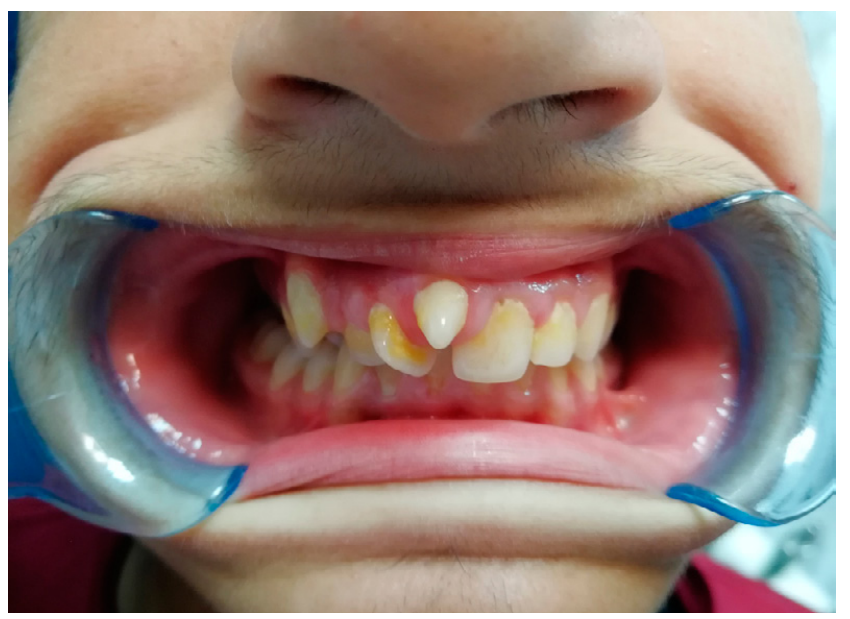

Figure 1. A facial image displaying a buccally located conical mesiodens

may occur singly or paired, erupted, or impacted. They are more commonly seen in the permanent dentition than in the primary. Mesiodentes are consistently reported as the most commonly observed supernumerary teeth (Tab. 1). Its incidence is reported to range between $0.13-1.6 \%$ [20-27] with a 1.5-2.8:1 predilection for occurrence in males [20-24, 27, 28 ]. Bilateral mesiodentes occur in $4-25.8 \%$ of all cases [ 20 , $21,23,24,29]$. Mesiodens are usually found unerupted [13, 21, $23,24,27]$, with a cone-shaped crown and a short root [20,21, $23,28,30]$. According to their shape (morphology) and size, there are two types of mesiodens, the first type is eumorphic, resembling the central incisors with normal shape and size. The second includes dysmorphic mesiodentes with variable sizes and shapes, and can be further subdivided (according to their morphology) into conical, tuberculate or molariform, of which the conical form is the most prevalent $[13,21$,

Table 1. Descending arrangement supernumeraries as reported by various studies

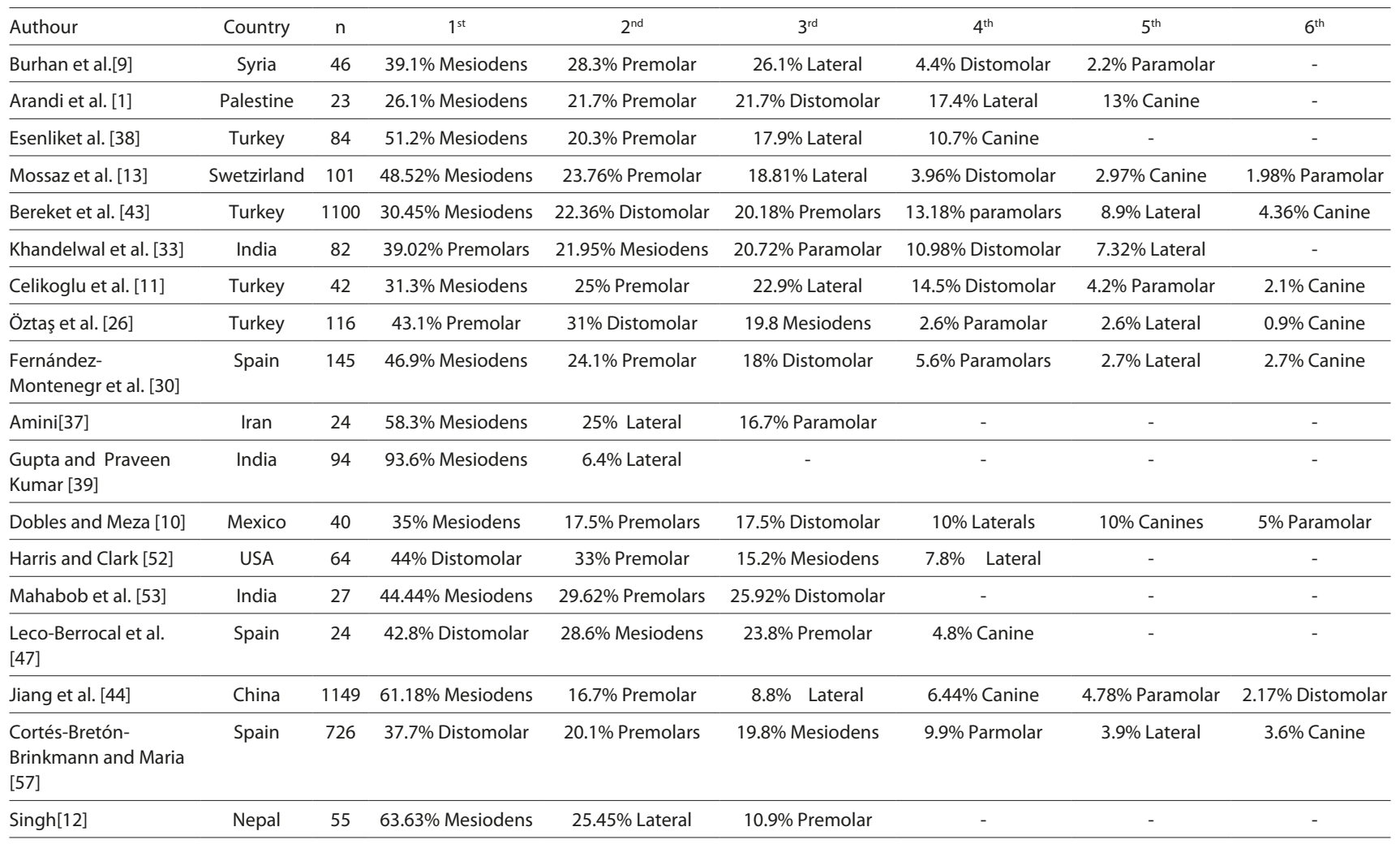




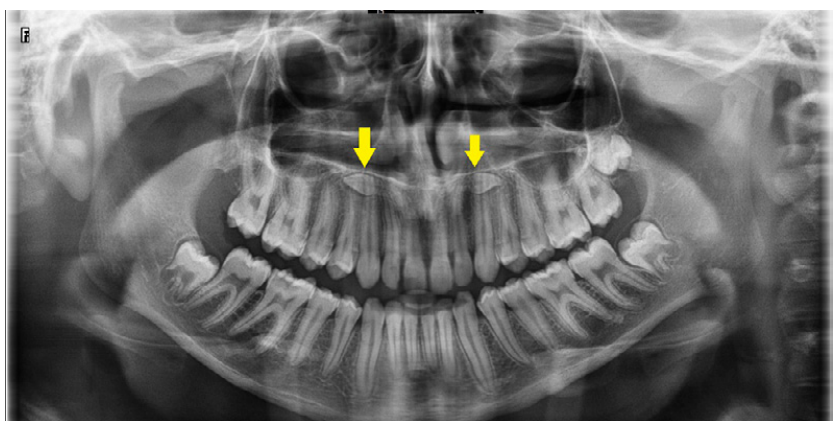

Figure 2. A panoramic radiograph showing two horizontally impacted mesiodentes

22, 27, 31, 32]. Most mesiodentes have been reported to occur palatal to the central incisors [23, 28, 30, 32]. Mossaz et al. reported that out of the 49 mesiodentes they studied, two (4.1\%) had a labial/buccal 'bucco-oral' position of the crown [13]. Studies report that the most common position is the vertical position $[13,20,21,24,27,33]$. Nevertheless, an inverted position is also common [23, 28, 34]. Asaumi et al. reported that of the 256 mesiodentes they studied, 172 (67\%) were inverted, $69(27 \%)$ in a normal direction, and $15(6 \%)$ in a horizontal direction against the axis of the tooth [28] (Fig. 2). Hyun et al. observed that $56.58 \%$ of the 1,200 mesiodentes they investigated were inverted, $27.33 \%$ were vertical, and $16.08 \%$ were horizontal [32]. The familial occurrence of mesiodens is well documented. In some cases, more than one sibling has been affected $[23,35]$. The anomaly has also been seen in more than one generation and sometimes skips a generation.

Less frequently, supernumerary teeth may be positioned between the central and lateral incisors or between lateral incisors and canines. Supernumerary lateral incisors occur more frequently in the maxilla than in the mandible [13, $36]$, and the majority occur unilaterally $[1,26,33,37,38]$, erupted $[1,25,33,38]$, and of the supplemental type $[1,10,33$, $38,39]$. Supernumerary lateral incisors are more frequently observed in males [1, 25, 33], although some studies have report them occurring more frequently in females [10], and sometimes equally $[36,37]$. Supernumerary lateral incisors are smaller than the adjacent normal lateral incisors, whereas the normal lateral incisors adjacent to supernumerary ones are smaller than the contralateral incisors [36]. Supplemental lateral incisors are rare, and almost all the cases of supernumerary lateral incisors reported in the literature were erupted. However, Hekmatfar et al. reported the case of bilaterally impacted supplemental supernumerary lateral incisor in a 9-year-old male [40]. Andrei et al. reported the case of an impacted unilateral supernumerary lateral incisor in a 5-year-old female [41]. The prevalence of supernumerary lateral incisors has been described to occur within the range of $0.05-1.59 \%[1,10,25,26,33,37,38,42]$.

Although there are numerous studies in the literature investigating the characteristics of various types of supernumerary teeth, only a few focus on supernumerary canines. They are detected more often in the maxilla than in the mandible [13, 43-46] (Fig. 3) and may occur mainly in the form of small conical-shaped teeth [44]. However, a study reported them to have almost an equal percentage of supplemental and conical shapes [26]. Cortés-BretónBrinkmann et al. [46] reported that of the 26 supernumeraries in their study, 14 (53.85\%) had supplemental morphology and 12 (46.15\%) heteromorphic morphology.

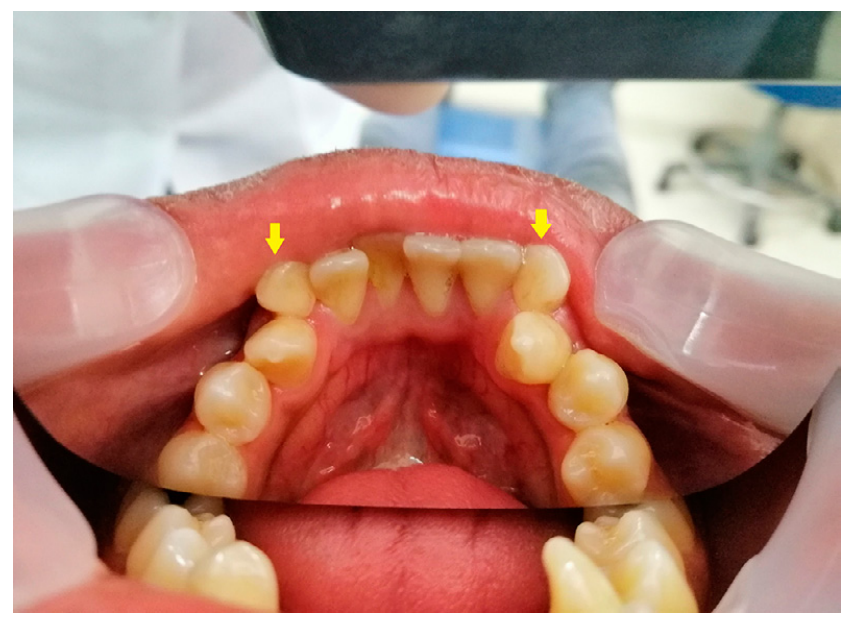

Figure 3. An image showing a case of mandibular bilateral supernumerary canines

Supernumerary canines are extremely rare. Among 21,615 Spanish patients, 22 with 26 supernumerary canines were diagnosed presenting a prevalence of $0.10 \%$ [46]. In a study conducted among 5,200 Turkish patients, only one was diagnosed with a supernumerary canine [26]. Among 1,038 Mexican individuals, supernumerary canines were found only in three [10]. In an investigation involving 60,104 Chinese adults, $6.44 \%(n=74)$ of the 1,149 supernumeraries detected were supernumerary canines [44]. The corresponding figure in a Brazilian study of 460 supernumerary teeth amounted to $3.8 \%(n=17)$ [45]. Fernández Montenegro et al.[30] found four supernumerary canines among 145 supernumerary teeth (2.75\%), but Leco Berrocal et al.[47] obtained a higher percentage in their sample (4.17\%), although the study only included 24 supernumerary teeth. Many other studies did not discover any supernumerary canines in their study populations (Tab. 1).

Supernumerary premolars. Supernumerary premolars are 'extra' teeth morphologically belonging to the premolar group $[17,18]$, and are usually reported in patients older than 12 years of age [30]; cases of late-developing supernumerary premolars have also been reported [48]. Supernumerary premolars can be unilateral, bilateral, single, or multiple [17]. Supernumeraries in the premolar region are usually of the supplemental type $[8,13,30,49]$. However, Küchler et al. reported that $80 \%$ of all the supernumerary premolars detected in their study were tuberculated in shape [50]. The prevalence of supernumerary premolars varies between $0.09 \%-0.76 \%[17,18,51,52]$, and are reported to be more common in males than in females [17]. Supernumerary premolars occur more frequently in the mandible than in the maxilla $[18,51]$ (Fig. 4). Studies report that $57-90 \%$ of all detected supernumerary premolars from various studies were mandibular $[8,1,38,45,51-54]$ and are the most common supernumerary teeth in the mandible $[45,47$, 53]. Still, the prevalence of supernumerary teeth occurring in the mandibular premolar region is quite low [55]. The orientation of a supernumerary premolar might be vertical, mesio-inclined, disto-inclined, and inverted. Arikan et al. reported that of the 16 supernumerary premolars detected in their study population ( $\mathrm{n}=7551), 10(62.5 \%)$ were vertically oriented [8]. Bilateral cases are more common than the unilateral [51, 55] (Fig. 5). Mandibular bilateral cases are more common than maxillary [51,55] (Fig. 4). Kaya et al. reported 


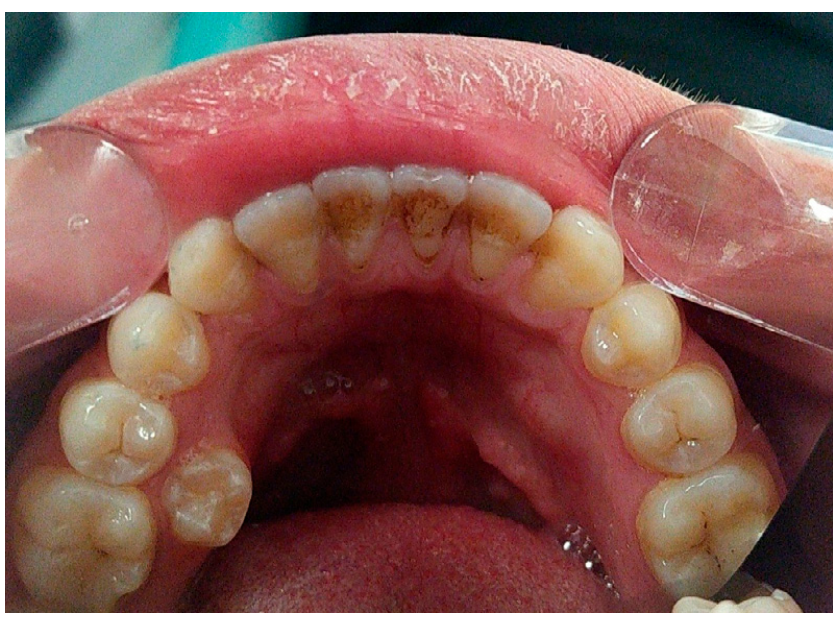

Figure 4. An image showing a unilateral lingually-positioned mandibular supernumerary premolar

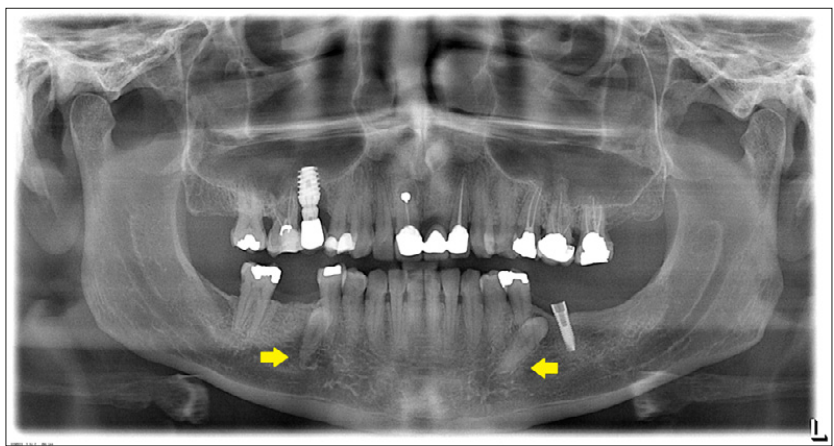

Figure 5. A panoramic x-ray showing a case of bilaterally impacted mandibular supernumerary premolars

that $75 \%(n=20)$ of the unilateral cases of supernumerary premolars were on the right side [51].

Supernumerary molars. Supernumerary molars are either para- or distomolars. Paramolars are located distally to the first molar, but outside the dental arcade, either buccally or lingually, while distomolars are found distally to the third molar and generally in line with the dental arch. Distomolars are more common than paramolars $[9,11,13,26,30,43$, $56,57]$. In contrast, Jiang et al. reported that paramolars $(68.8 \%)$ were more common than distomolars [44]. Similarly, Khandelwal et al. observed paramolars (17/26; 65.38\%) more common than distomolars [33]. Distomolars (also referred to as fourth molars) are reported with a prevalence of $0.03-2.1 \%$ [56, 58-66]. Distomolars primarily occur singly; bilateral occurrence is rare $[58-60,66]$. Distomolars occur most frequently in the maxilla $[58,59,63]$ (Fig. 6). Distomolars have a male predilection $[58,59,61]$, although Bamgbose et al. have reported that distomolars occurred in their study sample with approximately equal frequency in males and females [63]. The occurrence of distomolars has also been reported with almost equal frequency in the left and right sides [58, 60, 66, 67]; however, two studies have reported distomolars more commonly on the right side of the maxilla [43, 61], and others have observed that distomolars are more common on the left side of the mandible $[43,60]$. Distomolars are usually impacted $[43,58-60,63,66]$. In contrast, Casettee et al. reported that only three out of 24 distomolars observed in 25,186 Italian Caucasian patients

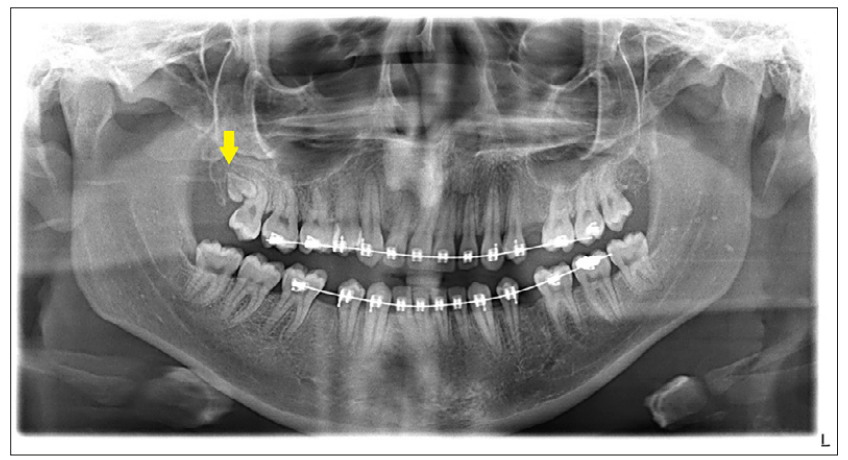

Figure 6. A panoramic x-ray showing an impacted distomolar on right side of the maxilla

were impacted, while the others were erupted [62]. A distomolar may have a normal morphology with a completely developed crown, single root, distinct from the adjacent third molar, or it can differ from its normal morphology $[43,56$, $58-62,66]$. Studies report that a major percentage of the distomolars detected were of a molariform (tuberculated) shape $[43,59,61]$. On the other hand, other reports state that distomolars are mainly peg-and conical-shaped, and smaller than the maxillary third molar [58, 62].

Paramolars are relatively uncommon with a prevalence of $0.036-0.13 \%[9,10,26,33,37,56]$, and occur most frequently in the maxilla $[13,26,37,43,56]$. One study reported equal occurrence in both jaws [44]. Paramolars primarily occur singly; bilateral occurrence is rare [26]. Paramolars have a female predilection $[37,56,64]$. The prevalence of paramolar teeth was slightly higher on the left side than on the right side $[26,43,56]$. Jiang et al. observed that $41.8 \%$ of the paramolars $(n=55)$ they detected were tuberculate and $36.4 \%$ were of the supplemental type [44]. Bereket et al. reported that the majority $(96 / 145)$ of paramolars detected in their study were of the tuberculate form [43]. Two other studies reported that the majority of the paramolars they detected were conical, followed by tuberculated and then supplemental forms $[33,56]$. Khandelwal et al. reported that 10 out of 17 paramolars were conical [33], while Ostaz et al. [26] and Fernández-Montenegro et al. [30] reported that the majority of paramolars they observed were of the rudimentary form.

Wide variations in the prevalence figures of supernumerary teeth have been reported in the literature. In addition to racial variations, the age difference in the patients studied and the different diagnostic and data collection methods used by the investigators may explain this wide range of prevalence. Table 1 shows the reported differences in the percentages of different types of supernumeraries (based on their location) in various studies.

\section{CONCLUSIONS}

The characteristics, and prevalence figures of each type of supernumerary tooth varies within and between different ethnicities and study populations. However, supernumerary teeth may cause aesthetic, functional, and occlusal problems; therefore, early diagnosis, proper treatment planning and interdisciplinary intervention are important to minimize consequences to the developing dentition. Clinicians should be aware of such signs as delayed eruption, alterations 
in the eruptive pattern, shift in the midline, or dental crowding.

\section{REFERENCES}

1. Arandi NZ, Abu-Ali A, Mustafa S. Supernumerary Teeth: A Retrospective Cross-Sectional Study from Palestine. Pesqui Bras Odontopediatria Clin Integr. 2020; 20: 1-9.

2. Mallineni SK, Kumar S. Supernumerary Teeth: Review of the Literature with Recent Updates. Conf Pap Sci. 2014; 2014: 1-6.

3. Fekonja A. Prevalence of dental developmental anomalies of permanent teeth in children and their influence on esthetics. J Esthet Restor Dent. 2017; 29(4): 276-83.

4. Laganà G, Venza N, Borzabadi-Farahani A, Fabi F, Danesi C, Cozza P Dental anomalies: Prevalence and associations between them in a large sample of non-orthodontic subjects, a cross-sectional study. BMC Oral Health. 2017; 17(1): 1-7.

5. Shokri A, Poorolajal J, Khajeh S, Faramarzi F, Kahnamoui HM Prevalence of dental anomalies among 7- to 35-year-old people in Hamadan, Iran in 2012-2013 as observed using panoramic radiographs. Imaging Sci Dent. 2014; 44(1): 7.

6. Hagiwara Y, Uehara T, Narita T, Tsutsumi H, Nakabayashi S, Araki M. Prevalence and distribution of anomalies of permanent dentition in 9584 Japanese high school students. Odontology. 2016; 104(3): 380-9.

7. Vani NV, Saleh SM, Tubaigy FM, Idris AM. Prevalence of developmental dental anomalies among adult population of Jazan, Saudi Arabia. Saudi J Dent Res. 2016; 7(1): 29-33.

8. Arikan V, Ozgul BM, Oz FT. Prevalence and Characteristıcs of Supernumerary Teeth in a Child Population from Central Anatolia Turkey. Oral Heal Dent Manag. 2013; 12(4): 2-5.

9. Burhan AS, Nawaya FR, Arabi Katbi ME, Al-Jawabra AS. Prevalence of supernumerary teeth in a nonsyndromic Syrian sample. J Egypt Public Health Assoc. 2015; 90(4): 146-9.

10. Dobles NJ, Meza RS. Prevalence of supernumerary teeth in a mexican sample. Rev Mex Ortod. 2015; 3(2): e88-91.

11. Celikoglu M, Kamak H, Oktay H. Prevalence and characteristics of supernumerary teeth in a non-syndrome Turkish population: Associated pathologies and proposed treatment. Med Oral Patol Ora Cir Bucal. 2010; 15(4): 4-7.

12. Singh VP, Sharma A, Sharma S. Supernumerary Teeth in Nepalese Children. Sci World J. 2014; 2014.

13. Mossaz J, Kloukos D, Pandis N, Suter VGA, Katsaros C, Bornstein MM. Morphologic characteristics, location, and associated complications of maxillary and mandibular supernumerary teeth as evaluated using cone beam computed tomography. Eur J Orthod. 2014; 36(6): $708-18$.

14. Subasioglu A, Savas S, Kucukyilmaz E, Kesim S, Yagci A, Dundar M. Genetic background of supernumerary teeth. Eur J Dent. 2015; 9(1): $153-8$.

15. Khambete N, Kumar R. Genetics and presence of non-syndromic supernumerary teeth: A mystery case report and review of literature. Contemp Clin Dent. 2012; 3(4): 499-502.

16. Cammarata-scalisi F, Avendano A, Callea M. Main genetic entities associated with supernumerary teeth. Arch Argent Pediatr. 2018; 116(6): 437-43.

17. Arandi NZ. Non-syndromic Supernumerary Premolars, a Literature Review and a Report of Two Cases. Int J oral care Res. 2019; 6: 44-8.

18. Khalaf K, Al Shehadat S, Murray CA. A Review of Supernumerary Teeth in the Premolar Region. Int J Dent. 2018; 2018: 1-5.

19. Sarne O, Shapira Y, Blumer S, Finkelstein T, Naomi S, Nir B. Supernumerary Teeth in the Maxillary Anterior Region: The Dilemma of Early Versus Late Surgical Intervention. J Clin Pediatr Dent. 2018; 42(1): 54-60

20. Gunduz K, Celenk P, Zengin Z, Sumer P. Mesiodens: a radiographic study in children. J Oral Sci. 2008; 50(3): 287-91.

21. Kazanci F, Celikoglu M, Miloglu O, Yildirim H, Ceylan I. Short Communication The Frequency and Characteristics of Mesiodens in a. Eur J Dent. 2011; 5(July): 361-5.

22. Altan H, Akkoc S, Altan A. Radiographic characteristics of mesiodens in a non-syndromic pediatric population in the Black Sea region. J Investig Clin Dent. 2018; (September): e12377.

23. Tyrologou S, Koch G, Kurol J. Location, complications and treatment of mesiodentes - A retrospective study in children. Swed Dent J. 2005; 29(1): 1-9.
24. Lara TS, Lancia M, Silva Filho OG da, Garib DG, Ozawa TO. Prevalence of mesiodens in orthodontic patients with deciduous and mixed dentition and its association with other dental anomalies. Dental Press J Orthod. 2013; 18(6): 93-9.

25. Anibor E, Mabiaku Y, Inikoro C. Prevalence of Supernumerary Teeth in a Nigerian Population. Int J Forensic Med Invest. 2015; 1(1): 7-9.

26. Öztaș B, Bardak C, Kurșun EŞ, Akbulut N. Clinical characteristics of non-syndromic supernumerary teeth in a cohort of Turkish patients. Oral Radiol. 2011; 27(2): 108-13

27. Erdem AP, Ak G. The prevelance of mesiodens in a group of nonsyndromic Turkish children: a radiographic study. 2018; 52(June 2017): $162-6$.

28. Asaumi J, Shibata Y, Yanagi Y, Hisatomi M, Matsuzaki H, Konouchi $\mathrm{H}$, et al. Radiographic examination of mesiodens and their associated complications. Dentomaxillofacial Radiol. 2004; 33(2): 125-7.

29. Altan H, Akkoc S, Altan A. Radiographic characteristics of mesiodens in a non-syndromic pediatric population in the Black Sea region. J Investig Clin Dent. 2018; (September): e12377.

30. Fernández Montenegro P, Valmaseda Castellón E, Berini Aytés L, Gay Escoda C. Retrospective study of 145 supernumerary teeth. Med Oral Patol Oral Cir Bucal. 2006; 11(4): E339-44.

31. Villavicencio J, Hernandez J, Medina S. Clinical Variations of Double Mesiodens: A Review and Case Report. Rev Fac Odontol Univ Antioquia. 2015; 27(1): 216-27.

32. Hyun H-K, Lee S-J, Lee S-H, Hahn S-H, Kim J-W. Clinical Characteristics and Complications Associated With Mesiodentes. J Oral Maxillofac Surg. 2009; 67(12): 2639-43.

33. Khandelwal P, Rai AB, Bulgannawar B, Hajira N, Masih A, Jyani A. Prevalence, characteristics, and morphology of supernumerary teeth among patients visiting a dental institution in Rajasthan. Contemp Clin Dent. 2018; 9(3): 349-56.

34. Zhao L, Liu S, Zhang R, Yang R, Zhang K, Xie X. Analysis of the distribution of supernumerary teeth and the characteristics of mesiodens in Bengbu, China: a retrospective study. Oral Radiol. 2020; (0123456789): 3-8.

35. Vecchione Gurgel C, Soares Cota AL, Yuriko Kobayashi T, Moura Bonifácio Silva S, Aparecida Andrade Moreira Machado M, Rios D, et al. Bilateral Mesiodens in Monozygotic Twins: 3D Diagnostic and Management. Case Rep Dent. 2013; 2013: 1-5

36. Wedrychowska-Szulc B, Janiszewska-Olszowska J. The supernumerary lateral incisors-morphology and concomitant abnormalities. Ann Acad Stetin. 2007; 53(3): 107-13.

37. Amini F. Prevalence and Pattern of Accessory Teeth (Hyperdontia) in Permanent Dentition of Iranian Orthodontic Patients. Iran J Public Health. 2013; 42(11): 1259-65.

38. EsenlikE, Sayin MÖ, Atilla AO, Özen T, Altun C, BaşakF. Supernumerary teeth in a Turkish population. Am J Orthod Dentofac Orthop. 2009; 136(6): 848-52.

39. Gupta S, Praveen Kumar P. A Study on Prevalence, Complications, and Possible Etiologic Factors of Supernumerary Teeth in 6-12-year-old Schoolchildren of Rohtak, India. Indian J Dent Sci. 2019; 11(2): 10-3.

40. Hekmatfar S, Badkash S, Jafari K. Bilateral supernumerary maxillary lateral incisors: A rare case report. J Oral Heal Oral Epidimiology. 2015; 4(1): 46-50.

41. Andrei OC, Farcaşiu C, Mărgărit R, Dinescu MI, Tănăsescu LA, Dăguci L, et al. Unilateral supplemental maxillary lateral incisor: report of three rare cases and literature review. Rom J Morphol Embryol. 2019; 60(3): 947-53.

42. Cristina BD, Bratu E, Mariana P, Popa G, Silvia P. The Prevalence of Supernumerary Teeth in a Group of Patients in Western Romania. Acta Marisiensis Ser Medica. 2012; 57(6): 581-4.

43. Bereket C, Cakir-Özkan N, Șener I, Bulut E, Baştan A. Analyses of 1100 supernumerary teeth in a nonsyndromic Turkish population: A retrospective multicenter study. Niger J Clin Pract. 2015; 18(6): 731-8.

44. Jiang Y, Ma X, Wu Y, Li J, Li Z, Wang Y, et al. Epidemiological, clinical, and 3-dimentional CBCT radiographic characterizations of supernumerary teeth in a non-syndromic adult population: a singleinstitutional study from 60,104 Chinese subjects. Clin Oral Investig. 2020; X(X): X

45. De Oliveira Gomes C, Drummond SN, Jham BC, Abdo EN, Mesquita RA. A survey of 460 supernumerary teeth in Brazilian children and adolescents. Int J Paediatr Dent. 2008; 18(2): 98-106.

46. Cortés-Bretón-Brinkmann J, Martínez-Rodríguez N, Barona-Dorado C, Martín-Ares M, Sanz-Alonso J, Suárez-García MJ, et al. Clinical repercussions and epidemiological considerations of supernumerary canines: A 26 case series. Med Oral Patol Oral y Cir Bucal. 2019; 24(5): e615-20. 
47. Leco Berrocal MI, Martín Morales JF, Martínez González JM. An observational study of the frequency of supernumerary teeth in a population of 2000 patients. Med Oral Patol Oral Cir Bucal. 2007; 12(2): 134-8.

48. Paduano S, Rongo R, Lucchese A, Aiello D, Michelotti A, Grippaudo C. Case Report Late-Developing Supernumerary Premolars: Analysis of Different Therapeutic Approaches. Case Rep Dent. 2016; 2016(1): 1-8.

49. Chou ST, Chang HP, Yang YH, Lung CY, Tseng YC, Pan CY, et al. Characteristics of supernumerary teeth among nonsyndromic dental patients. J Dent Sci. 2015; 10(2): 133-8.

50. Küchler EC, Costa AG Da, Costa MDC, Vieira AR, Granjeiro JM. Supernumerary teeth vary depending on gender. Braz Oral Res. 2011; 25(1): 76-9.

51.Kaya G-Ş, Yapıcı G, Ömezli M-M, Dayı E. Non-syndromic supernumerary premolars. Med Oral Patol Oral Cir Bucal. 2011; 16(4): e522-5.

52. Harris EF, Clark LL. An epidemiological study of hyperdontia in American blacks and whites. Angle Orthod. 2008; 78(3): 460-5.

53. Mahabob MN, Anbuselvan GJ, Kumar BS, Raja S, Kothari S. Prevalence rate of supernumerary teeth among non-syndromic South Indian population: An analysis. J Pharm Bioallied Sci. 2012; 4(Suppl 2): S373-5.

54. Durmuslar M, Misir A, Demiriz L. Prevalence and characteristics of supernumerary teeth: A survey on 7348 people. J Int Soc Prev Community Dent. 2015; 5(7): 39.

55. O'Dowling I. Supernumerary pre-molar teeth in the mandible. J Ir Dent Assoc. 2009; 55(6): 293-5.

56. Kara MI, Aktan AM, Ay S, Bereket C, Șener I, Bülbül M, et al. Characteristics of 351 supernumerary molar teeth in Turkish population. Med Oral Patol Oral Cir Bucal. 2012; 17(3): 1-6.

57. Brinkmann JC, María NM. Epidemiological Features and Clinical Repercussions of Supernumerary Teeth in a Multicenter Study: A Review of 518 Patients with Hyperdontia in Spanish Population. Eur J Dent. 2020; X(X): 1-8.
58. Kaya E, Gungor K, Demirel O, Ozge O. Prevalence and characteristics of non-syndromic distomolars: a retrospective study. J Investig Clin Dent. 2015; 6(4): 282-6.

59. Kurt H, Suer TB, Senel B, Avsever H. A retrospective observational study of the frequency of distomolar teeth in a population. Cumhur Dent J. 2015; 18(4): 335-42.

60. Arslan A, Altundal H, Ozel E. The frequency of distomolar teeth in a population of urban Turkish adults: A retrospective study. Oral Radiol. 2009; 25(2): 118-22.

61. Thomas SA, Sherubin E, Pillai KS. A Study on the Prevalence and Characteristics of Distomolars among 1000 Panoramic Radiographs. J Indian Acad Oral Med Radiol. 2013; 25(September): 169-72.

62. Cassetta M, Altieri F, Giansanti M, Di-Giorgio R, Calasso S. Morphological and topographical characteristics of posterior supernumerary molar teeth: An epidemiological study on 25,186 subjects. Med Oral Patol Oral Cir Bucal. 2014; 19(6): e545-9.

63. Bamgbose BO, Okada S, Hisatomi M, Yanagi Y, Takeshita Y, Abdu ZS, et al. Fourth molar: A retrospective study and literature review of a rare clinical entity. Imaging Sci Dent. 2019; 49: 27-34.

64. Cholakova R. Clinical and Epidemiological Study of supernumerary teeth in patients from plovdiv region. Acta Medica Bulg. 2020; XLVII(2): 22-6.

65. Arandi NZ. Distomolars: An overview and 3 case reports. Dent Oral Craniofacial Res. 2017; 4(1): 1-3

66. Gopakumar D, Thomas J, Ranimol P, Vineet DA, Thomas S, Nair VV. Prevalence of supernumerary teeth in permanent dentition among patients attending a dental college in South Kerala: A pilot study. J Indian Acad Oral Med Radiol. 2014; 26(1): 15-8.

67. Mitsea A, Vardas E, Papachatzopoulou A, Kalfountzos G, Leventis M, Tsiklakis K. The frequency of non-syndromic distomolar teeth in a Greek population sample? J Clin Exp Dent. 2015; 7(5): 589-94. 